\title{
TREADMILL GAIT ANALYSIS OF REHABILITATED AND INDEPENDENT LOWER-LIMB AMPUTEES
}

doi: 10.2478/v10038-012-0023-4

\section{SORAIA CRISTINA TONON DA LUZ *, ALUISIO OTAVIO VARGAS ÁVILA, MARIO CÉSAR DE ANDRADE, BEATRIZ CONCEIÇÃO SILVA ALVES RODRIGUES}

State University of Santa Catarina, Santa Catarina, Brazil

\begin{abstract}
Purpose. A description of gait analysis during overground locmotion has been the subject of various studies, in relation to describing both the kinetic and spatial-temporal characteristics of walking. Measuring the gait of amputees using treadmills is a useful test to quantify locomotive ability, and a tool that helps to control gait parameters during rehabilitation. The aim of this study is to describe the kinetic and spatial-temporal characteristics of gait of rehabilitated amputees, measured with an instrumented treadmill. Methods. Twenty-four participants aged between 20 and 40 years were chosen, who had all suffered unilateral traumatic amputation either above or below the knee, and were classified as well-rehabilitated. Following a paperbased assessment form, the participants were subjected to gait analysis on an instrumented treadmill fitted with two force platforms. Results. The first peak vertical force of intact and amputated limbs presented higher values and was significantly $(\mathrm{p} \leq 0.05)$ larger than the second peak vertical force for the amputated limb, indicating less propulsion during walking. A significant difference was observed in the load rate in intact and amputated limbs, indicating more overload in the intact limb. The spatial-temporal variables, cadence, step and stride length were significantly greater $(\mathrm{p} \leq 0.05)$ in the below-knee than in the above-knee amputees. Conclusions. The kinetic and spatial-temporal characteristics of gait, measured with an instrumented treadmill, which were observed in all lower limb amputees involved in this study, were similar to the ones commonly reported in numerous studies on overground walking. Thus, treadmill gait training and control of the progress of rehabilitation with amputees is recommended.
\end{abstract}

Key words: amputation, gait, treadmill

\section{Introduction}

Amputation of the lower limb not only affects the ability to walk, but also has an impact on the ability of the individual to participate in various activities [1], on body image perception [2], and on quality of life in general [3]. Furthermore, a reduction in the capacity for walking with a prosthesis is associated with a decrease in carrying out activities of daily living [4]. The walking abilities of amputees requires great effort and has a heterogeneous and multifactorial origin, encompassing the general health of the individual who has undergone amputation and the influence of various contextual factors including age, sex, co-morbidity, social support and physiological factors [5].

Riley et al. [6] commented that a treadmill is a tool that helps to control walking speed, allowing for a more meaningful comparison of the kinetic parameters between sessions.

The most basic instrumented treadmills measure only one component of the ground reaction force, typically the vertical force [1-3]. Few studies report that treadmill walking is equivalent to overground walking in healthy subjects $[7,8]$.

\footnotetext{
* Corresponding author.
}

Some authors [6,9-11] expressed the opinion that there are no clear differences between treadmill and overground gait and concluded that the mechanics are very similar. In contrast, several other authors $[12,13]$ pointed out several differences [14], particularly that walking on a treadmill increases cadence and decreases the support period, the variability of the steps and several kinematic components.

Gait analysis on the treadmill and overground is used both in scientific approaches for investigating the neuronal organization and ontogenetic development of locomotion, and in a variety of clinical applications [12]; however, the description of the gait parameters of amputees walking on an instrumented treadmill have not been reported.

Measuring walking speed of amputees with different levels of amputation is a useful test to quantify locomotor abilities during the progression of rehabilitation [15-18].

Most studies with amputees on a treadmill report the energetic expenditure required for walking and compare this expenditure in different levels of amputation $[8,19]$ or in different outdoor walking conditions [7]. Gait analysis performed on instrumented treadmills with well-rehabilitated and independent lower limb amputees provides kinetic and spatial-temporal information relevant for the development of methodo- 
logies which could help multidisciplinary rehabilitation teams. This contribution refers to the increase of ability, independence and safety during gait training, with the goal of achieving the fullest locomotor potential according to the level of amputation, age and activity level.

The purpose of this study was to describe the kinetic and spatial-temporal characteristics of the gait of rehabilitated and independent amputees, measured with an instrumented treadmill.

The hypothesis of this study is based on this question: Are the gait parameters of amputees with different levels of amputation similar to those commonly reported in numerous studies on overground walking?

\section{Material and methods}

This study examined twenty-four participants with unilateral amputation (14 below-knee and 10 aboveknee). The inclusion criteria for the present study were as follows: participants should have no associated health problems known to affect gait and/or balance, should not present decompensated hypertension or orthopaedic problems including arthritis or ligament problems in the intact knee, should be aged between 20 and 40 years, should present below-knee or aboveknee amputation or knee disarticulation due to trauma. The following inclusion criteria classified the subjects as well-rehabilitated: the absence of problems with the amputation stump, such as wounds, pain and hypertrophic scars; no problems with the prosthetic socket, such as excessive pressure, looseness or noises during walking; participants should carry out daily activities independently; should use a prosthesis for more than five years, should be with the same prosthesis for at least one year; and have no self-reported problems with alignment; nor should they have changed any of the components of the prosthesis in the month prior to testing.

The unilateral amputees used the same prosthetic components:

Above-knee amputation: CAT-CAM-type socket, 3R46 polycentric hydraulic knee, dynamic response feet (1D10)

Below-knee amputation: KBM-type socket with silicone and distal attachment, dynamic response feet (1D10).

The present study was approved by the ethics committee of the State University of Santa Catarina and conformed to the Helsinki Declaration of the World Medical Association. All of the subjects signed a Term of Free and Informed Consent. Data acquisition was performed at the Biomechanics Laboratory of CEFIDUDESC in Florianópolis-SC, Brazil.

An assessment form was employed to obtain personal details, the time since amputation, the time of adaptation to the prosthesis, and to check for fulfillment of the inclusion criteria of the study.

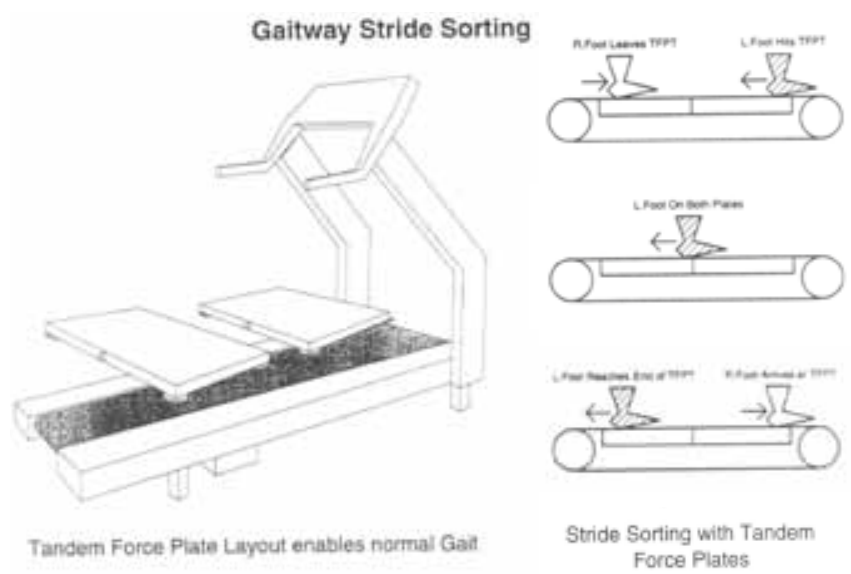

Figure 1. Treadmill Gait

The Kistler Gaitway Instrumented Treadmill System $^{\mathrm{TM}}$ (Fig. 1) was used for treadmill gait assessment. It is a piezoelectric ground reaction force measurement system which is able to measure vertical ground reaction forces for complete, consecutive, multiple foot strikes during walking and running. It has been designed using a tandem force plate design (one plate in front of the other) and includes an algorithm which distinguishes left from right strikes. The system consists of the Gaitway software system data acquisition board, a dual force plate instrumented treadmill with an eight-channel charge amplifier, six user defined inputs, a foot discriminator circuit and a belt speed sensor.

This equipment allows the participants to easily set the walking speed. It also reports real time data through the Gaitway software, which enables the experimenter to inform the participants of the results of their evaluation immediately after the test. After an adjustment period of walking on the treadmill (about 10 minutes), the participants self-selected a comfortable speed. Data were collected with an acquisition frequency of $100 \mathrm{~Hz}$, ten repetitions in a one-minute walk for each acquisition.

The number of repetitions was chosen based on the regularity of the dynamic and temporal standard of gait, the recording of the graphs of vertical force, and also the smallest standard deviation possible among the data collected.

The variables were described taking into consideration the prosthetic limb (PL) and the intact limb (IL) and the choice of them was based on those most commonly used in studies of gait vertical force. The kinetic variables (Fig. 2) refer to the behavior of the vertical ground reaction force: first force peak (FFP) corresponds to the period just after the heel touches the force plate and the center of gravity is traveling down toward the ground resulting in an increased reaction force from the ground in the vertical direction, while second force peak (SFP) corresponds to the toe pushing off the force plate applying a force onto the ground which is matched by an increase in the ground reaction force, while the 


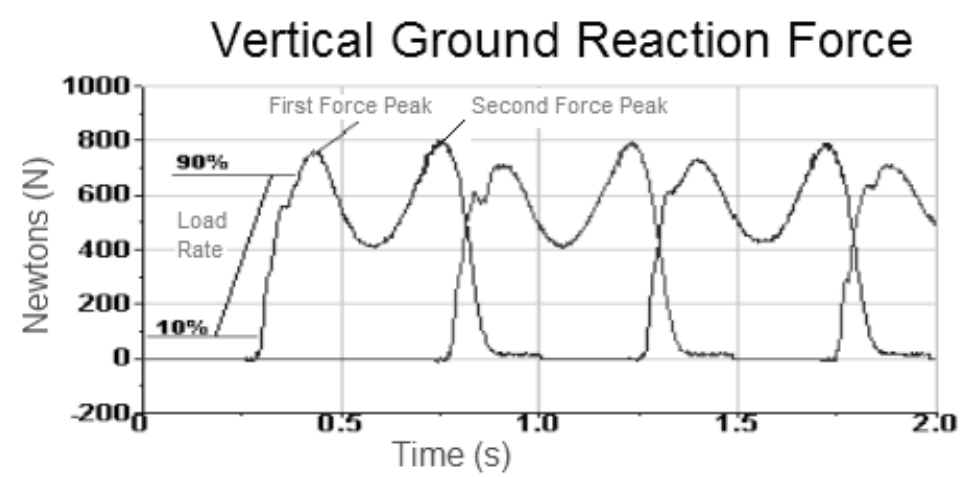

Figure 2. Graph of vertical ground reaction force representing the Load Rate, First Force Peak and Second Force Peak weight acceptance rate or Load rate (LR) represents the rate of change of ground force (from heel strike to FFP). The spatial-temporal variables were measurements of temporal and length relationships: cadence (CAD), step time (Tstep), step length (Lstep), stride time (Tstride), stride length (Lstride).

Statistical analysis included analysis of variance (ANOVA) with two factors, the level of amputation and prosthesis, for the variables FFP, SFP, LR, CAD, Lstep, Tstep, Lstride and Tstride. Walking speed was subjected to analysis of variance (ANOVA) with a single factor: the level of amputation. Pearson's linear correlation coefficient was calculated for the variables LR and CAD for the pairs (prosthetic limb and intact limb).

Significance level was fixed at $0.05(p \leq 0.05)$.

There are two limitations that need to be acknowledged regarding the present study. The first limitation concerns the difficulty of obtaining participants who meet the group inclusion criteria, since the subjects should be classified as well-rehabilitated. The second limitation was the impossibility of performing overground gait analysis to compare the data.

\section{Results}

Table 1 presents the participants' characteristics including age, body mass, height, gender, time since amputation and duration of using the prosthesis. No significant differences were observed between the two groups (below-knee and above-knee) on age, height, body mass, time since amputation and duration of using of prosthesis.

For the 24 individuals with unilateral amputation it was possible to obtain the highest peak force, and in which limb it occurred, by calculating the difference between the first and second peak (Tab. 2), in the limb with the prosthesis and in the intact limb as follows: FFP (PL) - SFP (PL ), FFP (IL) - SFP (IL). We observed statistically significant higher values for the FFP in the

Table 1. Characteristics of amputee participants - Mean (SD)

\begin{tabular}{|c|c|c|c|c|c|c|}
\hline $\begin{array}{l}\text { Amputation Level/ } \\
\text { Subjects }(N)\end{array}$ & Age (years) & Height $(\mathrm{cm})$ & Body Mass (kg) & $n /$ Gender & $\begin{array}{l}\text { Time since } \\
\text { amputation } \\
\text { (years) }\end{array}$ & $\begin{array}{c}\text { Duration of } \\
\text { prosthesis use } \\
\text { (years) }\end{array}$ \\
\hline $\mathrm{BK}(n=14)$ & $29.35(6.0)$ & $169(0.05)$ & $70.86(8.9)$ & $\begin{array}{r}3 \mathrm{~F} \\
11 \mathrm{M}\end{array}$ & $10.6(1.2)$ & $9.4(0.65)$ \\
\hline $\mathrm{AK}(n=10)$ & $34.2(4.6)$ & $170(0.04)$ & $71.67(9.2)$ & $\begin{array}{r}2 \mathrm{~F} \\
8 \mathrm{M}\end{array}$ & $13.4(0.7)$ & $11.7(1.2)$ \\
\hline
\end{tabular}

BK - Below-Knee; AK - Above-Knee; M - masculine; F - feminine

Table 2. Mean (SD) kinetic data for peak vertical ground reaction force $(\mathrm{N} / \mathrm{kg})$ and weight acceptance rate $(\mathrm{N} / \mathrm{Kg} / \mathrm{s})$ on treadmill gait

\begin{tabular}{lcccccc}
\hline $\begin{array}{l}\text { Amputees } \\
\text { Participants }\end{array}$ & \multicolumn{2}{c}{ SFP - FFP } & $\begin{array}{c}\text { One-Way ANOVA } \\
F \text { and } p \text { values }\end{array}$ & \multicolumn{2}{c}{ Load Rate } & \multicolumn{2}{c}{$\begin{array}{c}\text { One-Way ANOVA } \\
F \text { and } p \text { values }\end{array}$} \\
\hline Prosth & Intact & (Prosth/Intact) & Prosth & Intact & (Prosth/Intact) \\
\hline BK $(n=14)$ & $0.10(0.10)$ & $0.03(0.06)$ & $(\mathrm{BK} / \mathrm{AK})$ & $7.35(0.7)$ & $10.80(1.6)$ & $(\mathrm{BK} / \mathrm{AK})$ \\
\hline AK $(n=10)$ & $0.21(0.15)$ & $0.03(0.13)$ & $\begin{array}{l}F=2.94 \\
p=0.09\end{array}$ & $7.90(1.6)$ & $15.69(3.2)$ & $F=1.94$ \\
$p=0.16$ & \\
\hline
\end{tabular}

SFP - Second Vertical Force Peak; FFP - First Vertical Force Peak; BK - Below-Knee; AB - Above-Knee significant difference at $p \leq 0.05$ 


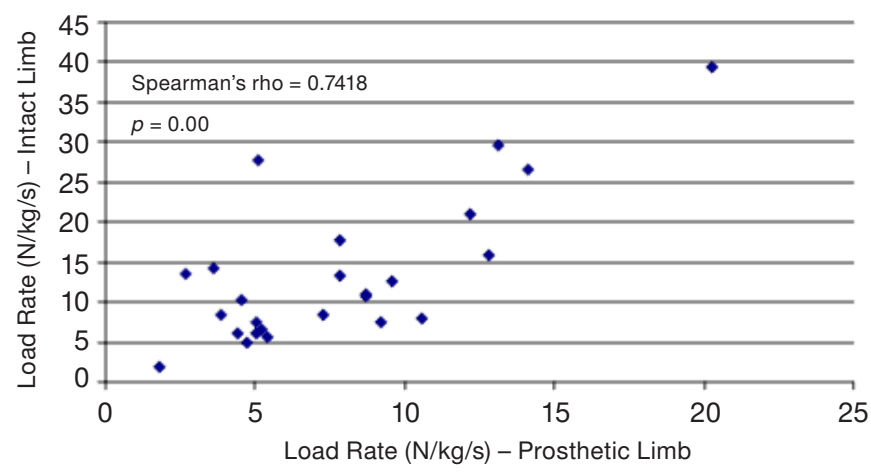

Figure 3. Graph of dispersion for Load Rate in Intact Limb and Prosthetic Limb on treadmill gait

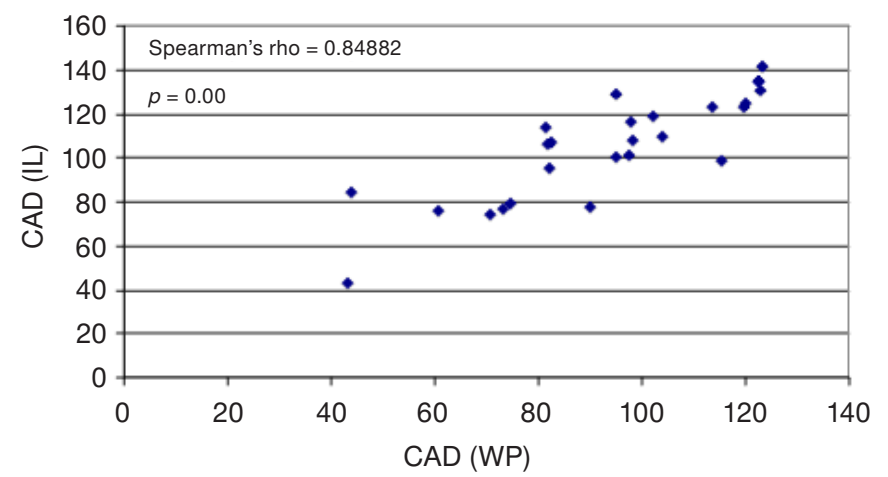

Figure 4. Graph of dispersion for cadence (CAD). WP - with prosthesis; IL - intact limb on treadmill gait

Table 3. Mean (SD) walking speed and temporal-spatial treadmill gait parameters

\begin{tabular}{|c|c|c|c|c|c|c|}
\hline Amputee participants & \multicolumn{2}{|c|}{$\mathrm{BK} n=14$} & \multicolumn{2}{|c|}{$\mathrm{AK} n=10$} & \multicolumn{2}{|c|}{$p$ value (BK/AK) } \\
\hline \multirow[t]{3}{*}{ Walking speed (m/s) } & \multicolumn{2}{|c|}{$1.07(0.06)$} & \multicolumn{2}{|c|}{$1.01(0.1)$} & \multicolumn{2}{|c|}{0.13} \\
\hline & \multirow[t]{2}{*}{ Prosth } & \multirow[t]{2}{*}{ Intact } & \multirow[t]{2}{*}{ Prosth } & \multirow[t]{2}{*}{ Intact } & \multicolumn{2}{|c|}{$\begin{array}{c}\text { One-Way ANOVA } \\
F \text { and } p \text { values }\end{array}$} \\
\hline & & & & & $(\mathrm{AK} / \mathrm{BK})$ & (Prosth/Intact) \\
\hline Cadence (steps/min) & $101.6(5.3)$ & $110.3(6.0)$ & $84.2(7.1)$ & $98.1(7.0)$ & $\begin{array}{l}F=5.42 \\
p=0.024\end{array}$ & $\begin{array}{l}F=3.17 \\
p=0.08\end{array}$ \\
\hline Step length (m) & $0.66(0.02)$ & $0.71(0.02)$ & $0.60(0.02)$ & $0.64(0.02)$ & $\begin{array}{l}F=6.01 \\
p=0.0001\end{array}$ & $\begin{array}{l}F=3.63 \\
p=0.06\end{array}$ \\
\hline Step time (s) & $0.90(0.25)$ & $0.98(0.27)$ & $0.86(0.36)$ & $1.0(0.35)$ & $\begin{array}{l}F=0.01 \\
p=0.91\end{array}$ & $\begin{array}{l}F=1.65 \\
p=0.20\end{array}$ \\
\hline Stride length (m) & $1.26(0.02)$ & $1.29(0.02)$ & $1.19(0.01)$ & $1.18(0.02)$ & $\begin{array}{l}F=13.55 \\
p=0.0001\end{array}$ & $\begin{array}{l}F=0.08 \\
p=0.77\end{array}$ \\
\hline Stride time (s) & $1.09(0.02)$ & $1.06(0.02)$ & $1.12(0.01)$ & $1.07(0.03)$ & $\begin{array}{l}F=7.37 \\
p=0.009\end{array}$ & $\begin{array}{l}F=28.68 \\
p=0.0001\end{array}$ \\
\hline
\end{tabular}

BK - Below-Knee; AB - Above-Knee; significant difference $(p \leq 0.05)$

limb with the prosthesis, indicating little impact absorption in this limb.

There was a strong linear correlation for load rate among the 24 unilateral amputees (Fig. 3), while the mean values in the intact limb and prosthetic limb were significantly different, indicating that the intact limb presented a higher load rate and, consequently, more overload.

The treadmill spatial-temporal parameters for all participants with two levels of amputation are presented in Table 3. There was no significant difference between the walking speed of the below-knee group and that of the above-knee group.

The linear correlation of cadence in the intact limb and prosthetic limb was found to be strong (Fig. 4), with a significant difference between the below-knee and above-knee levels, indicating lower cadence in transfemoral amputees group.

The mean values for step length, stride length and stride time are presented in Table 2 and Figure 5, which show significant differences between below-knee and above-knee levels. Comparing the intact limb and prosthetic limb, the step and stride length variables were not significantly different. The variable stride time, the mean values for step length, stride length and the mean of stride time, were significantly different between below-knee and above-knee levels and the intact limb and prosthetic limb indicating greater stride time in the transfemoral amputees and the prosthetic limb.

\section{Discussion}

During walking on the treadmill it was observed that there was no significant difference between the speed of the below-knee and above-knee amputation groups, even though several studies on overground gait analysis demonstrated higher speeds in the case of below-knee amputations [20-23].

Numerous studies with overground walking $[17,18$, 

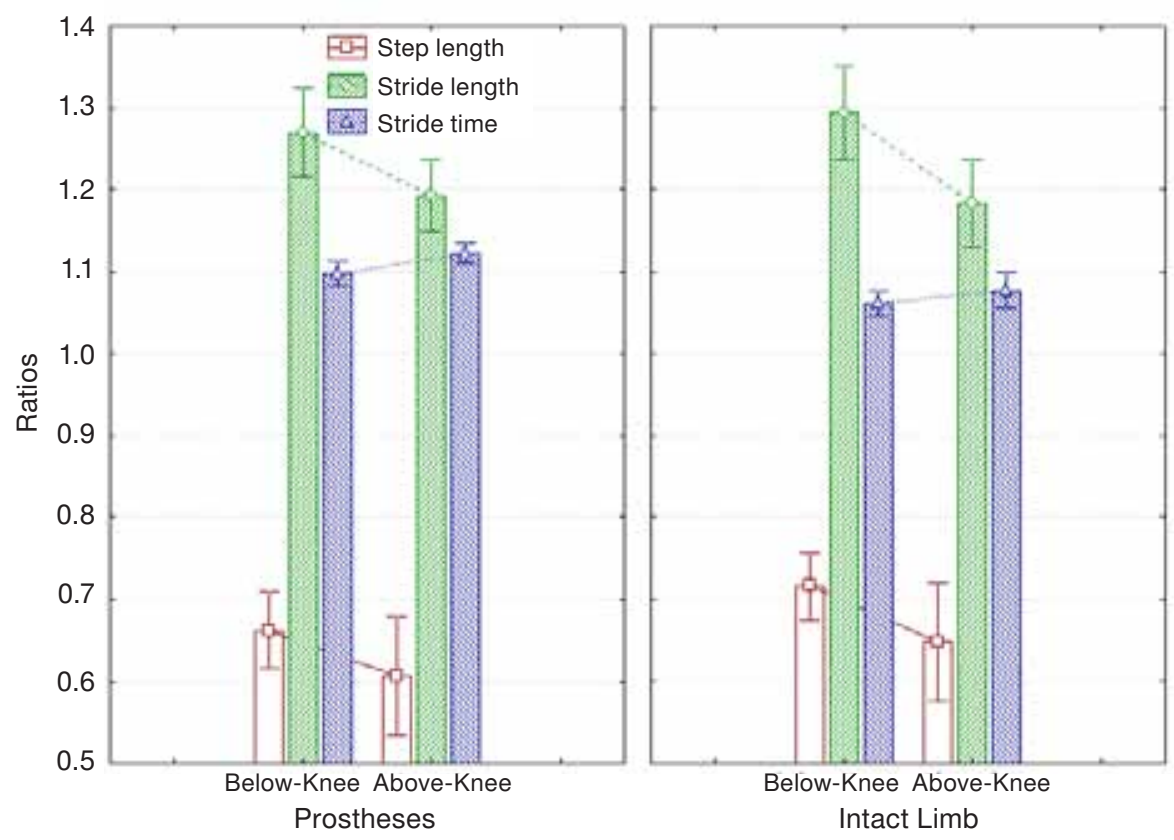

Figure 5. Graph of step length, stride length and stride time, for two levels of amputation: below-knee and aboveknee, with and without prosthesis on treadmill gait
$20,24,25]$ have reported that in below-knee and aboveknee amputees the vertical ground reaction force is smaller in the prosthesis limb when compared to the intact limb, indicating less propulsion during walking. Here, the difference between force peaks (FFP - SFP), which was significantly greater for the prosthetic limb, indicated the same characteristics: little toe-off in this active phase of gait. A series of reports in overground walking has shown that the heel strike and the toe-off of the prosthetic foot were inadequate and generated a compensatory response in the intact limb in both periods of double support $[17,18,26-28]$, and associated this with many factors: muscle weakness in the residual limb, altered sensitivity in the amputation stump, difficulty in controlling the prosthetic knee, and inefficiency of the components of the prosthetic foot. Other authors such as Silverman et al. [18] state that increasing hip extensor strength and output in the residual leg may be a useful mechanism to reduce vertical ground reaction force loading asymmetry between the intact and residual legs. Amputees have an increased risk of developing joint disorders in the intact leg due to an increased dependence on this limb $[29,30]$. The importance of preventing these diseases must be noted, as it has been suggested that the age at the time of amputation has an adverse effect on walking potential. The analysis of this study identified that the loading rate during treadmill walking in individuals with unilateral amputation was higher in the intact limb with low propulsion of the prosthetic limb. We associate this fact to the lack of stability or equilibrium of the prosthetic limb, which causes a greater burden on the intact limb when its heel starts to hit the treadmill. It has been reported, in studies of overground gait, that unilateral amputees prefer to use the intact limb for weight discharge with a consequent decrease in speed of move- ment $[20,23,31]$. The findings suggest that reducing the speed of movement is important to protect the healthy limb against stress and repeated trauma, especially in patients whose etiology of amputation is vascular.

Some authors, such as Fey et al. [32] state that exceeding the loading rate on the intact limb and the low level of propulsion with the prosthetic limb are due to muscle imbalance. They studied changes in muscle activity in below-knee amputees in response to increased walking speed and found that the differences occurred in the biceps femoris - the long head of the residual limb, the vastus lateralis and the rectus femoris. They commented that these adaptations are consistent with the need for additional support in order to propel the body forward in the absence of plantar flexors.

We observed that the spatial-temporal variables, cadence, step and stride length were significantly greater $(p \leq 0.05)$ in below-knee than in above-knee amputees. Some studies [21, 22], associated with gait kinetic analysis of overground walking, clarify that the asymmetries in spatial-temporal parameters in below-knee subjects, compared to above-knee subjects, may be explained by maintaining the functional integrity of the knee joint, controlling the swing phase and activating a strong lever to achieve hip extension with this level of amputation.

In this study, the participants were classified as wellrehabilitated according to the inclusion criteria and all individuals were independent in terms of carrying out daily activities and leisure using proper prosthetic components.

However, the asymmetries found in kinetic and spatial-temporal variables in two levels of amputation, investigated here on an instrumented treadmill, have been reported in the literature for overground walking.

We thereby emphasize, in particular, that the maintenance of these characteristics in the long term may 
be highly damaging to the intact joints and suggest that intervention in the rehabilitation process of the amputee should focus on protecting the intact limb from weight overload. Gait training of amputees on instrumented treadmills can facilitate the rehabilitation of walking with a prosthesis by means of increasing control over the asymmetries in the studied parameters as well as preventing injury, especially of the intact limb.

\section{Conclusion}

The present data strongly suggest that the kinetic and spatio-temporal characteristics of gait, measured with an instrumented treadmill, observed in rehabilitated and independent amputees with different levels of amputation, were similar to the results commonly reported in numerous studies of overground gait. Thus, treadmill gait training and control of the progress of rehabilitation with amputees is recommended.

\section{References}

1. Tonon S.C., Avila A.O.V.A., Gait analysis in amputees with different level of amputation. Rev Bras Biomec, 2000, 1, 27-31.

2. Gallagher P., Horgan O., Franchignoni F., Giordano A., MacLachlan M., Body image in people with lower-limb amputation: a Rasch analysis of the Amputee Body Image Scale. Am J Phys Med Rehabil, 2007, 86 (3), 205-215, doi: 10.1097/PHM.0b013e3180321439.

3. Pell J.P., Donnan P.T., Fowkes F.G., Ruckley C.V., Quality of life following lower limb amputation for peripheral arterial disease. Eur J Vasc Surg, 1993, 7 (4), 448-451.

4. Collin C., Wade D.T., Cochrane G.M., Functional outcome of lower limb amputees with peripheral vascular disease. Clin Rehabil, 1992, 6 (1), 13-21, doi: 10.1177/026921559 200600103.

5. Sansam K., Neumann V., O’Connor R., Bhakta B., Predicting walking ability following lower limb amputation: a systematic review of the literature. J Rehabil Med, 2009, 41 (8), 593-603, doi: 10.2340/16501977-0393.

6. Riley P.O., Paolini G., Della Croce U., Paylo K.W., Kerrigan D.C., A kinematic and kinetic comparison of overground and treadmill walking in healthy subjects. Gait Posture, 2007, 26 (1), 17-24, doi: 10.1016/j.gaitpost. 2006.07.003.

7. Starholm I.M., Gjovaag T., Mengshoel A.M., Energy expenditure of transfemoral amputees walking on a horizontal and tilted treadmill simulating different outdoor walking conditions. Prosthet Orthot Int, 2010, 34 (2), 184-194, doi: 10.3109/03093640903585016.

8. Waters R., Perry J., Antonelli D., Hislop H., Energy cost of walking of amputees: the influence of level amputation. J Bone Joint Surg Am, 1976, 58 (1), 42-46.

9. Murray M.P., Spurr G.B., Sepic S.B., Gardner G.M., Mollinger L.A., Treadmill versus floor walking: kinematics, electromyogram, and heart rate. J Appl Physiol, 1985, 59 (1), 87-91.

10. Barbeau H., Locomotor training in neurorehabilitation: emerging rehabilitation concepts. Neurorehabil Neural Repair,2003,17(1),3-11,doi:10.1177/0888439002250442.
11. Owings T.M., Grabiner M.D., Step width variability, but not step length variability or step time variability, discriminates gait of healthy young and older adults during treadmill locomotion. J Biomech, 2004, 37 (6), 935-938, doi: 10.1016/j.jbiomech.2003.11.012.

12. Stolze H., Kuhtz-Buschbeck J.P., Mondwurf C., BoczekFuncke A., Jöhnk K., Deuschl G., Illert M., Gait analysis during treadmill and overground locomotion in children and adults. EEG Clin Neurophysiol, 1997, 105 (6), 490-497.

13. Alton F., Baldey L., Caplan S., Morrissey M.C., A kinematic comparison of overground and treadmill walking. Clin Biomech, 1998, 13 (6), 434-440, doi: 10.1016/ S0268-0033(98)00012-6.

14. Dingwell J.B., Cusumano J.P., Cavanagh P.R., Sternad D., Local dynamic stability versus kinematic variability of continuous overground and treadmill walking. J Biomech Eng, 2001, 123 (1), 27-32.

15. Jaergers S.M., Arendzen J.H., Jongh H.J., Changes in hip muscles after above-knee amputation. Clin Orthop Relat Res, 1995, 319, 276-284.

16. Courtemanche R., Teasdale N., Boucher P., Fleury M., Lajoie Y., Bard C., Gait problems in diabetic neuropathic patients. Arch Phys Med Rehabil, 1996, 77 (9), 849-855, doi: 10.1016/S0003-9993(96)90269-5.

17. Vanicek N., Strike S., McNaughton L., Polman R., Gait patterns in transtibial amputee fallers vs. non-fallers: Biomechanical differences during level walking. Gait Posture, 2009, 29 (3), 415-420, doi: 10.1016/j.gaitpost. 2008.10.062.

18. Silverman A.K., Fey N.P., Portillo A., Walden J.G., Bosker G., Neptune R.R., Compensatory mechanisms in below-knee amputee gait in response to increasing steadystate walking speeds. Gait Posture, 2008, 28 (4), 602-609, doi: 10.1016/j.gaitpost.2008.04.005.

19. Perry J., Gait analysis: Normal and pathological function. Slack Inc., Thorofare, NJ, USA, 1992, 192-195.

20. Vrieling A.H., Keeken H.G., Schoppen V., Otten E., Halbertsma J.P.K., Hof A.L., Postema K., Obstacle crossing in lower limb amputees. Gait Posture, 2007, 26 (4), 587-594, doi: 10.1016/j.gaitpost.2006.12.007.

21. Oberg K., Lanshammar H., An investigation of kinematic and kinetic variables for the description of prosthetic gait using the ENOCH system. Prosthet Orthot Int, 1982,6(1),43-47, doi:10.3109/03093648209167740.

22. Skinner H., Effeney D., Gait analysis in amputees: special review. Am J Phys Med Rehabil, 1985, 64 (2), 82-89.

23. Rossi S.A., Doyle W., Skinner H.B., Gait initiation of persons with below-knee amputation: the characterization and comparison of force profiles. J Rehabil Res Dev, 1995, 32 (2), 120-127.

24. Torburn L., Perry J., Ayyappa E., Shanfield S.L., Belowknee amputee gait with dynamic elastic response prosthetic feet: a pilot study. J Rehabil Res Dev, 1990, 27 (4), 369-384.

25. Zuniga E.M., Leavitt L.A., Calvert J.C., Canzoneri J., Peterson C.R., Gait patterns in above-knee amputees. Arch Phys Med Rehabil, 1972, 53 (8), 373-382.

26. Isakov E., Mizrahi J., Bilateral simultaneous measurements of standing ground reaction forces in hemiparetics, below-knee amputees, and healthy adults. Basic Appl Myol, 1997, 7 (2), 97-101. 


\section{HUMAN MOVEMENT}

S.C. Tonon da Luz et al., Treadmill Gait analysis of amputees

27. Isakov E., Burger H., Krajnik J., Gregoric M., Marincek C., Double-limb support and step-length asymmetry in belowknee amputees. Scand J Rehab Med, 1997, 29 (2), 75-79.

28. Menard M.R., McBride M.E., Sanderson D.J., Murray D.D., Comparative biomechanical analysis of energy-storing prosthetic feet. Arch Phys Med Rehabil, 1992, 73 (5), 451-458.

29. Burke M.J., Roman V., Wright V., Bone and joint changes in lower limb amputees. Ann Rheum Dis, 1978, 37 (3), 252-254, doi:10.1136/ard.37.3.252.

30. Melzer I., Yekutiel M., Sukenik S., Comparative study of osteoarthritis of the contralateral knee joint of male amputees who do and do not play volleyball. J Rheumatol, 2001, 28 (1), 169-172.

31. Winter D.A., Sienko S.E., Biomechanics of below-knee amputee gait. J Biomech, 1988, 21 (5), 361-367, doi: 10.1016/0021-9290(88)90142-X.

32. Fey N.P., Silverman A.K., Neptune R.R., The influence of increasing steady-state walking speed on muscle activity in below-knee amputees. J Electromyogr Kinesiol, 2010, 20 (1), 155-161, doi: 10.1016/j.jelekin.2009.02.004.

Paper received by the Editors: June 29, 2011

Paper accepted for publication: July 4, 2012

\section{Correspondence address}

Soraia Cristina Tonon da Luz

Biomechanics Laboratory

Science Center for Health and Sport

State University of Santa Catarina

Paschoal Simone, 358

Florianópolis, Santa Catarina, Brazil

CEP: 88080-350

e-mail: soraiaudesc@hotmail.com 